\title{
Estimation of Renewable Energy Potential and Use- A Case Study of Hokkaido, Northern-Tohoku Area and Tokyo Metropolitan, Japan-
}

\author{
Tatsuya Wakeyama ${ }^{1, *}$, Sachio Ehara ${ }^{2}$ \\ ${ }^{1}$ Laboratory of Geothermics, Graduate School of Engineering, Kyushu University \\ ${ }^{2}$ Laboratory of Geothermics, Faculty of Engineering, Kyushu University \\ *Corresponding author. Tel: +81 928023324, Fax: +81 928023324, E-mail: tatsuya-wakeyama@mine.kyushu- \\ u.ac.jp
}

\begin{abstract}
The present work is intended to evaluate renewable energy potential in Northern Japan area and Tokyo metropolis and to reveal possibility of supplying renewable energy from Northern Japan area to Tokyo metropolis. This evaluation method consists of three processes with GIS. The first process is simulation of the meteorological parameters such as river discharge and direct solar radiation. The second process is extraction of potential areas with restrictions such as meteorological conditions, geographical features and social environment. The third process is calculation of annual energy production. The application of the new method to Northern Japan area shows that the sum of renewable energy potential is $185,000 \mathrm{GWh}$ /year, which contains 120,374 $\mathrm{GWh} /$ year of wind energy, 29,111 GWh/year of mini-micro hydropower, $986 \mathrm{GWh} /$ year of solar power, 31,089 $\mathrm{GWh}$ /year of geothermal energy and 3,440 GWh/year of biomass energy. The geothermal and biomass energy potential were quoted from earlier study. The renewable energy potential in Northern Japan area is bigger than the 78,519 GWh/year of electricity demand in civilian sector in Tokyo. It is possible for the renewable energy potential in Northern Japan area to satisfy electricity demand not only in Northern Japan area but also in Tokyo metropolis.
\end{abstract}

Keywords: Renewable Energy Potential Estimation, GIS, Wind Energy, Hydropower, Solar Energy

\section{Nomenclature}

$E_{p w}$ Wind energy potential.................. $k$ Wh.year ${ }^{-1}$

$V \quad$ Wind velocity .................................... $\mathrm{m} \cdot \mathrm{s}^{-1}$

$f(V)$ Weibull model ...........................................-

$P(V)$ Power curve ........................................... kW

$E_{p h}$ Mini-micro hydropower potential $k W h \cdot$ year $^{-1}$

$H$ Height. $m^{-1}$

Q River discharge $\mathrm{kg} \cdot \mathrm{s}^{-1}$

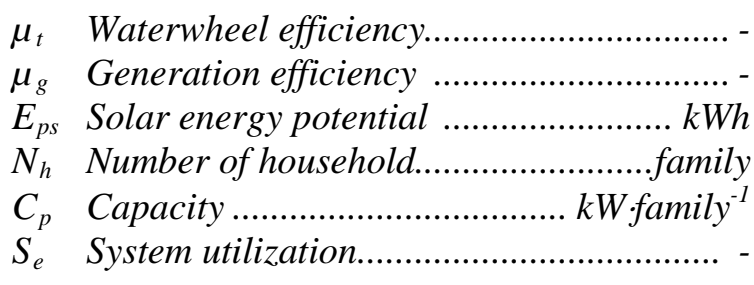

\section{Introduction}

The present work is intended to evaluate extensively renewable energy resources potential in Northern Japan area and Tokyo metropolis and to analyze locally renewable energy potential in Akita prefecture in order to reveal possibility of supplying renewable energy from Northern Japan area. In Japan, Tokyo metropolitan government and Northern Japan area, such as Aomori, Akita, Iwate, Yamagata and Hokkaido, have agreed on interregional cooperation for renewable energy use. The purpose of the agreement is to realize reducing $\mathrm{CO}_{2}$ emission in Tokyo metropolis and revitalization of the rural economy and expansion of job opportunities by supplying renewable energy from the rural area to the huge city. There are differences of circumstance between rural areas that have a huge renewable energy potential and a big city that has huge energy demand behind.

In order to efficiently construct renewable energy facilities the systematic and accurate evaluation of renewable energy potential is important. Voivontas et al., for example, developed a decision support system by using GIS (Geographical Information System) for the evaluation of renewable energy sources potential and conducted financial analysis of 
renewable energy investment in Crete, Greece [1]. The evaluation methods in earlier studies were designed locally for each specific area. In contrast, the authors intended to evaluate extensively renewable energy resources potential and to prove features in each area by comparison of evaluation results. Therefore the authors developed a new evaluation method by using GIS and publicly available digital spatial data in Japan [2].

\section{Methodology}

\subsection{Study area}

The study was carried out for Northern Japan area which includes Hokkaido and Tohoku area (Aomori, Akita, Iwate and Yamagata prefectures) and Tokyo metropolis in Japan. Fig. 1 shows that Hokkaido and Tohoku area lies in the northern part of Japan.

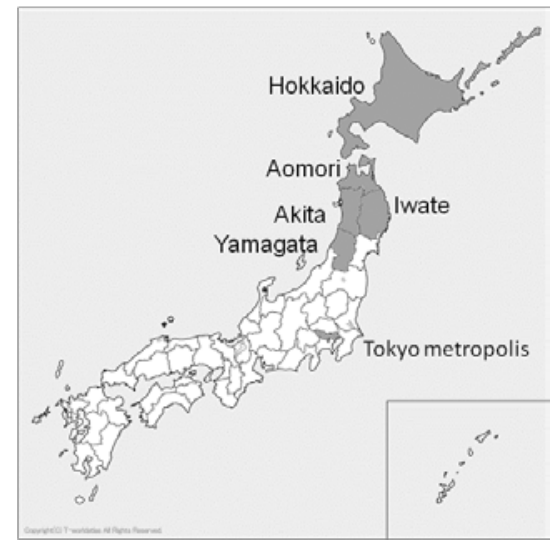

Fig. 1 Study area: Hokkaido, Tohoku area and Tokyo metropolis.

\subsection{Software and data source}

In the present work we used GRASS ver.5.3 and 6.2 as GIS software [3]. We also used GIS data from the database published by the Ministry of Land, Infrastructure, Transport and Tourism in Japan [4].We used $50 \mathrm{~m}$ grid elevation data, $1 \mathrm{~km}$ grid annual rainfall data, $100 \mathrm{~m}$ grid natural park data, $1 \mathrm{~km}$ grid number of family data, $100 \mathrm{~m}$ grid land use data and road vector data from the database.

\subsection{Concept of estimation}

In the renewable energy potential evaluation, we evaluate two kinds of potentials: "theoretical potential" and "practical potential." A theoretical potential is an amount that all energy potential theoretically exist, for example, all solar energy and wind power. A practical potential is an amount that potential is evaluated with restrictions such as climate conditions, geographical features and social environment. In the present work we evaluate the practical potential with a common small number of restrictions to prove features in each area.

\subsection{Procedure}

This new evaluation method consists of three processes. The first process is simulation of the meteorological parameters such as river discharge and direct solar radiation. The second process is extraction of potential areas with restrictions such as meteorological conditions, geographical features and social environment. The third process is calculation of annual energy production. In this process we develop a s cenario for calculation of the power generation facility, annual energy production and number of introducing facilities. 


\subsubsection{Wind energy}

First, wind property was quoted from the $500 \mathrm{~m}$ grid simulation result by NEDO [5]. Second, potential areas for wind energy were extracted under the consideration of the following restrictions;

- A minimum allowable wind speed of $5 \mathrm{~m} / \mathrm{s}$ ( in altitude of $30 \mathrm{~m}$ );

- A maximum distance from roads of $200 \mathrm{~m}$;

- A maximum slope from the level of 20 degrees;

- A maximum elevation of $1000 \mathrm{~m}$.

The following areas were not considered for the installation of wind turbine;

- Construction areas for houses;

- Natural parks and national parks.

Third, in order to calculate electrical output of wind power generation, we developed a scenario that wind electrical output was calculated with power curve. The power curve is in proportion to the cubic of wind velocity and approaches $1000 \mathrm{~kW}$ with $13 \mathrm{~m} / \mathrm{s}$ of wind velocity. Additionally, wind speed distributions were assumed as the Weibull model for calculation of annual energy production [5]. The number of introducing wind turbines was calculated on condition that wind turbines are set at $700 \mathrm{~m}$ interval in a potential area. The calculation for wind energy potential is described in Eq. (1). Wind energy potentials tend to be estimated bigger where extracted potential area is larger with this evaluation method.

$$
E_{p w}=\sum(f(V) \times p(V)) \times 8760
$$

where $E_{p w}$ is the wind energy potential, $V$ is the wind velocity, $f(V)$ is weibull model, $P(V)$ is power curve and 8760 is hours in a year.

\subsubsection{Mini-micro hydropower}

First, the river discharge was simulated from elevation and amount of an annual rainfall data with GRASS r.watershed module [3]. Second, potential areas for mini-micro hydropower were extracted under the consideration of the restriction that a minimum allowable river discharge is $0.01 \mathrm{~m}^{3} / \mathrm{s}$. Third, in order to calculate electrical output of mini-micro hydro electric generation, we developed a scenario that facilities is small scale hydropower: conduit type and afflux type power generation. This evaluation also assumed that hydro electric generators were set at $50 \mathrm{~m}$ interval in each river in the target area and that the heights of facilities were calculated from maximum slope data and $50 \mathrm{~m}$ grid digital elevation model data. Additionally, we assumed that outflow rate of water from rainfall to river discharge is $30 \%$ and that utilization ratio of river discharge is $20 \%$ for calculation of annual energy production. The calculation for mini-micro hydropower potential is described in Eq. (2). Mini-micro hydropower potentials tend to be estimated bigger where output per unit is huge with this evaluation method.

$$
E_{p h}=9.8 \times H \times Q \times 0.20 \times \mu_{t} \times \mu_{g} \times 8760 \div 1000
$$

where $E_{p h}$ is the mini-micro hydropower potential, 9.8 is the gravity acceleration, $H$ is height, $Q$ is river discharge and 0.20 is utilization ratio of river discharge $\mu_{\mathrm{t}}$ is waterwheel efficiency, $\mu_{\mathrm{g}}$ is generation efficiency, 8760 is hours in a year and 1000 is unit conversion from $\mathrm{W}$ to $\mathrm{kW}$. 


\subsubsection{Solar enegy}

First, the direct solar radiation was simulated from elevation data with GRASS r.sun module [3]. Second, potential areas for solar energy were extracted under the restriction that a minimum allowable direct solar radiation is $0.1 \mathrm{kWh} / \mathrm{m}^{2}$ a day. This restriction extracts almost all inhabitable areas as potential areas. Third, in order to calculate photovoltaic output, we developed a scenario that we introduce $1 \mathrm{~kW}$ photovoltaic cell to each household. Additionally, we assumed that PV system utilization is $12 \%$ for calculation of annual energy production. The number of introducing photovoltaic cell was calculated with number of household in each $1 \mathrm{~km}$ grid. The calculation for solar energy potential is described in Eq. (3). Solar power potentials tend to be estimated bigger where population is huge with this evaluation method.

$E_{p s}=N_{h} \times C_{p} \times S_{e} \times 8760$

where $E_{p s}$ is the solar energy potential, $N_{h}$ is Number of household, $C_{p}$ is capacity, $S_{e}$ is System utilization and 8760 is hours in a year.

\section{Potential evaluation result}

The results of renewable energy potential evaluation in Northern Japan area and Tokyo are summarized in Figs. 2 -4. These figures summarize each potential by each municipality and the municipalities in darker color have huge renewable energy potential.

\subsection{Wind energy potential evaluation}

Fig. 2 shows that each prefecture has several municipalities with huge wind power potential, which are over $1000 \mathrm{GWh} /$ year, in Northern Japan area. These municipalities with huge wind potential mainly locate along the coastline and the mountains. In Tokyo metropolis, a few municipalities have wind energy potential, which are smaller than $30 \mathrm{G} \mathrm{Wh}$ /year. Municipalities with large wind energy potential locate along the coastline in Tokyo.

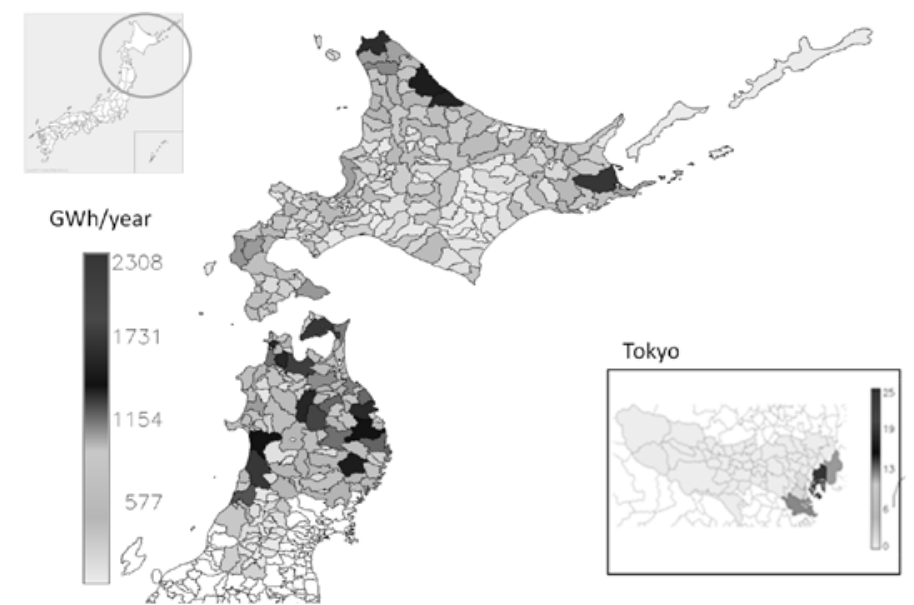

Fig. 2 Evaluation result of wind energy potential in Northern Japan area and Tokyo metropolis. 


\subsection{Mini-micro hydropower potential evaluation}

Fig. 3 shows that a few municipalities with huge mini-micro hydropower potential locate in Hokkaido and Yamagata, which are over $800 \mathrm{GWh} /$ year. Fig. 3 also indicates that many prefectures have large hydropower potentials, which are over $200 \mathrm{G} \mathrm{Wh} /$ year. These municipalities with large hydropower potential tend to be along the steep river with large river discharge and to have upper reach of a river. In Tokyo metropolis, municipalities with large mini-micro hydropower potential locate in western part of Tokyo. These municipalities have upper reach of a river and have mini-micro hydropower potential, which are around 100 GWh/year.

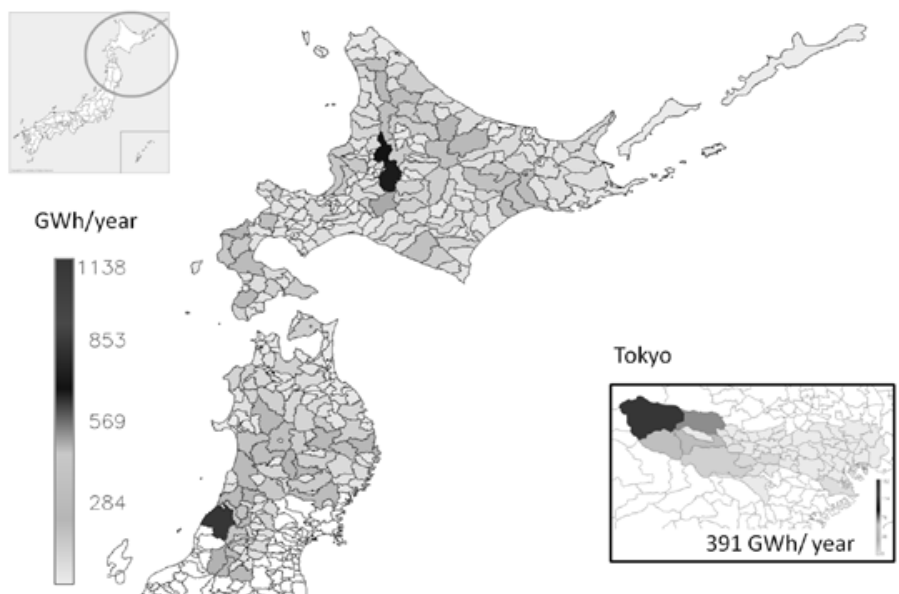

Fig. 3 Evaluation result of mini-micro hydropower potential in Northern Japan area and Tokyo metropolis.

\subsection{Solar energy potential evaluation}

Fig. 4 shows that a few municipalities with huge solar energy potential exist in Northern Japan areas, which are between $50 \mathrm{GWh} /$ year and $120 \mathrm{GWh} /$ year. These municipalities with large solar potential mainly locate along the coastline. In Tokyo metropolis, many municipalities have large solar energy potentials, which are over $50 \mathrm{GWh}$. Municipalities with large solar energy potentials locate in center area of Tokyo where populations are huge.

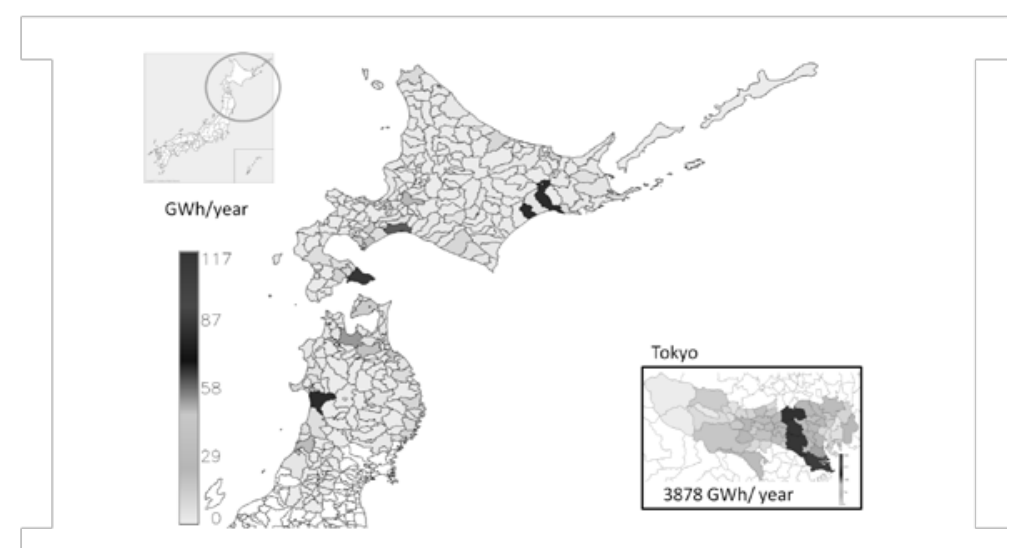

Fig. 4 Evaluation result of solar energy potential in Northern Japan area and Tokyo metropolis. 


\subsection{The sum of renewable energy potential}

Table 1 shows the sums of wind, solar and hydropower potential with geothermal and biomass energy potential in Northern Japan area and Tokyo metropolis. The geothermal potential is quoted from Geothermal Potential Map in Japan [6]. The biomass potential is quoted from Biomass GIS Database [7]. The sum of renewable energy potential in Northern Japan area is $185,000 \mathrm{GWh} /$ year, which contains $120,374 \mathrm{GWh} /$ year of wind energy, 29,111 $\mathrm{GWh} /$ year of mini-micro hydropower, $986 \mathrm{GWh} /$ year of solar power, 31,089 $\mathrm{GWh}$ /year of geothermal energy and 3,440 GWh/year of biomass energy. The sum of renewable energy potential in Tokyo metropolis is $8,168 \mathrm{G} \mathrm{Wh} /$ year, which contains $52 \mathrm{G} \mathrm{Wh} /$ year of wind energy, $391 \mathrm{GWh} /$ year of mini-micro hydropower, 3,878 GWh/year of solar energy, 675 $\mathrm{GWh} /$ year of geothermal energy and 3,173 GWh/year of biomass energy. On the other hand, Tokyo metropolis needs $78,519 \mathrm{GWh} /$ year of electricity demand in civilian sector [8]. The electricity demand of $78,519 \mathrm{GWh} /$ year in Tokyo is almost equivalent to ten times of 8,168 $\mathrm{GWh} /$ year of the renewable energy potential. It is difficult to satisfy the electricity demand in Tokyo with renewable energy potential in Tokyo. However, the renewable energy potential of $185,000 \mathrm{GWh} /$ year in Northern Japan area is enough to cover the electricity demand in civilian sector in Tokyo. It is important for Tokyo metropolis to make the most use of renewable energy potential in Northern Japan area in order to promote renewable energy use.

Table 1 Renewable energy potential evaluation result in Northern Japan area and Tokyo.

\begin{tabular}{ccccccc}
\hline (GWh/year) & Hokkaido & Aomori & Iwate & Akita & Yamagata & Tokyo \\
\hline Wind & 56608 & 21589 & 23315 & 13752 & 5111 & 52 \\
\hline $\begin{array}{c}\text { Mini-micro } \\
\text { hydropower }\end{array}$ & 13458 & 1778 & 5223 & 3398 & 5254 & 391 \\
\hline Solar & 598 & 178 & 53 & 120 & 37 & 3878 \\
\hline Geothermal & 20052 & 2330 & 3618 & 3005 & 2085 & 675 \\
\hline Biomass & 1510 & 491 & 532 & 506 & 401 & 3173 \\
\hline Sum & 92226 & 26366 & 32740 & 20780 & 12888 & 8168 \\
\hline
\end{tabular}

\subsection{Discussion on extensive renewable energy potential evaluation}

The evaluation results show that extensive renewable energy practical potential evaluation with a common small number of restrictions proves features of each area and that renewable energy potential in Northern Japan area is important resource not only for Northern Japan area but also Tokyo metropolis. However, these evaluation results are not efficient to plan the specific project, because the evaluation method evaluates only one aspect of the renewable energy potential. Therefore, the authors conducted more detailed potential analysis for use in Akita prefecture in order to analyze features of the evaluated potential.

\section{Wind energy potential analysis for use}

\subsection{Study area}

The extensive renewable energy evaluation result showed that there is huge wind energy potential in Northern Japan area and that the wind energy potential in Akita prefecture is one of most important renewable energy potential in Table 1 . Therefore, we analyzed locally wind energy potential with potential classification in Akita prefecture. The study area is Akita prefecture in Northern Japan area in Fig. 1. 


\subsection{Classification methodology of wind energy potential}

We classified wind energy potential in order to analyze how to make use of wind energy potential. In this study, we classified wind energy potential with mean annual wind speed of over $6.0 \mathrm{~m} / \mathrm{s}$ in altitude of $70 \mathrm{~m}$. The criteria for classification were decided based on feasibility of introducing wind energy facilities. In order to analyze feasibility of introducing wind energy facilities, the study area is divided into $10 \mathrm{~km}$ square grids. We compared properties of grids that have installed wind energy facilities with the other grids. We focused attention on pr operties of average elevation and average slope. The areas with higher elevation or slope value are concerned about the possibility of increasing construction costs.

Fig. 5 shows comparison of properties in grids with wind energy facilities between in grids with no wind energy facilities. Fig. 5 (a) is a comparison of average elevation and Fig. 5 (b) is a comparison of average slope in each grid. Fig. 5 (a) indicates that the grids with installed wind energy facilities have average elevation of lower than $500 \mathrm{~m}$. The relationship is consistent with tendency of lower elevation to be encouraged in planning introducing wind energy facilities. Figure 5 (b) indicates that the grids with installed wind energy facilities have average slope of lower than 15 degrees. The relationship is also consistent with tendency of lower slope to be encouraged in planning introducing wind energy facilities. Therefore, the areas with following properties are seen as a strong possibility of introducing wind energy facilities.

- Average elevation is lower than $500 \mathrm{~m}$ in the grid.

- Average slope is lower than 15 degrees in the grid.

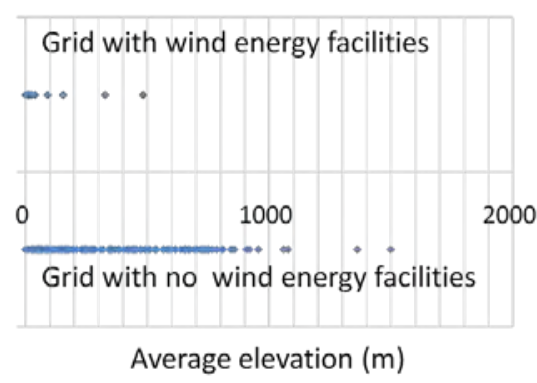

(a) Relationship between average elevation and installed wind energy facilities.

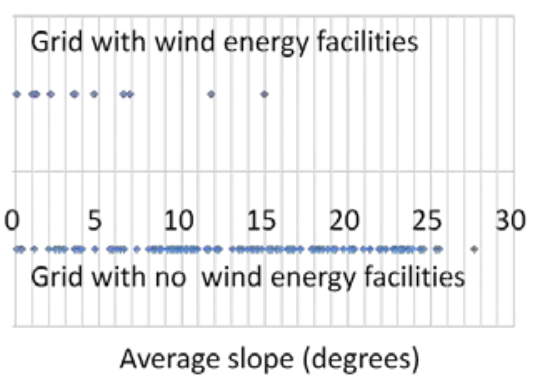

(b) Relationship between average slope and installed wind energy facilities.

Fig. 5 Comparison of properties in grids with wind energy facilities between in grids with no wind energy facilities.

\subsection{Classification result of wind energy potential}

Fig. 6 shows classification result of wind energy potential in Akita prefecture. Fig. 6 (a) shows the potential classified according to average elevation and average slope in Akita prefecture. Fig. 6 (a) shows the potential is $15,028 \mathrm{GWh} /$ year with a minimum allowable mean annual wind speed of $6.0 \mathrm{~m} / \mathrm{s}$ in altitude of $70 \mathrm{~m}$ in Akita prefecture. The wind energy potential of $15,028 \mathrm{GWh}$ /year includes potential of $11,090 \mathrm{GWh} /$ year with average elevation of lower than $500 \mathrm{~m}$ and average slope of lower than 15 de grees in each grid. On the other hand, the wind energy potential of $15,028 \mathrm{GWh} /$ year also includes potential of 1,069 $\mathrm{GWh} /$ year with average elevation of higher than $500 \mathrm{~m}$ and average slope of higher than 15 degrees in each grid. Fig. 6 (b) shows that the distribution of classification results in Akita prefecture. In Fig. 6 (b) darker gray shows hopeful grid. The hopeful grids colored with darker gray exist in several parts of Yamamoto area, Akita area, Yurihonjo area and Kazuno area, which are with lower elevation and slope. In fact, a portion of the wind energy potential is used there. In addition the grids with light gray exist around Kazuno area. The southern part 
of Kazuno has potential with lower elevation and higher slope. On the other hand the northern part of Kazuno has potential with higher elevation and lower slope.

\section{Conclusion}

The sum of renewable energy potential in Northern Japan area is 185,000 GWh/year, which contains $120,374 \mathrm{GWh} /$ year of wind energy, 29,111 GWh/year of mini-micro hydropower, $986 \mathrm{GWh} /$ year of solar power, 31,089 $\mathrm{GWh} /$ year of geothermal energy and 3,440 $\mathrm{GWh} /$ year of biomass energy. Tokyo has $78,519 \mathrm{GWh}$ /year of electricity demand, whereas only 8,168 $\mathrm{GWh} /$ year of total renewable energy potential. The renewable energy potential of 185,000 $\mathrm{GWh} /$ year in Northern Japan area is enough to cover the electricity demand in civilian sector in Tokyo. In Akita prefecture, wind energy potential of 11,090 GWh/year is with mean annual wind speed of over 6.0 , with average elevation of lower than $500 \mathrm{~m}$ and average slope of lower than 15 degrees in each grid. The hopeful wind energy potential exists in several parts of Yamamoto area, Akita area, Yurihonjo area and Kazuno area. It is possible for making use of the huge wind energy potential extensively there.

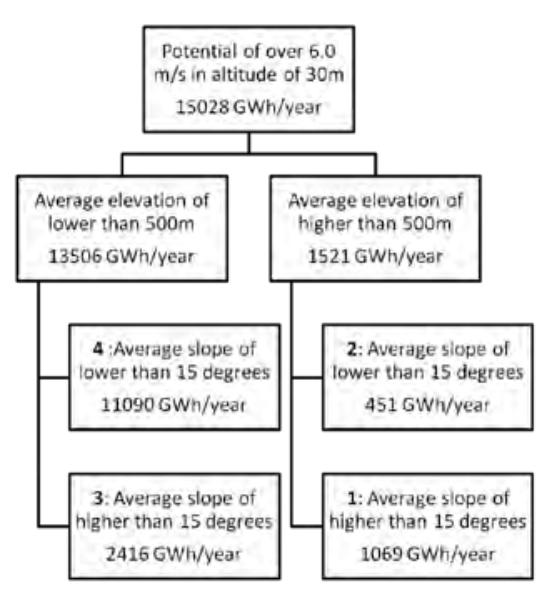

(a) potential classified according to elevation and slope

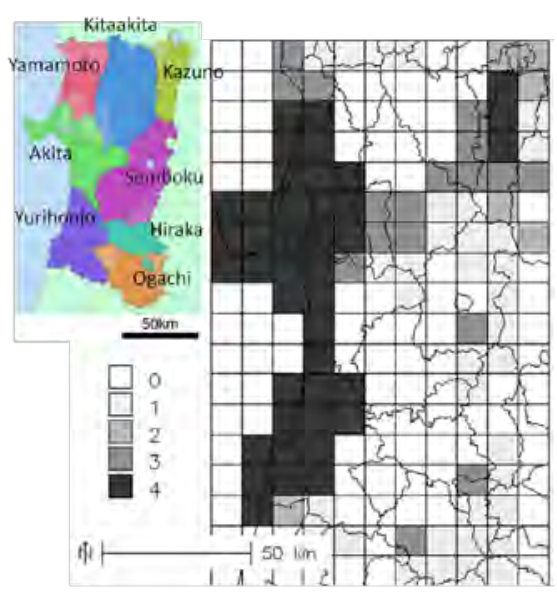

(a) Distribution of classification results

Fig. 6 Classification result of wind energy potential in Akita prefecture.

\section{References}

[1] D. Voivontas, D. Assimacopoulos, A. Mourelatos, J. Corominas, Evaluation of renewable energy potential using a GIS decision support system, Renewable Energy, 13, 1998, pp.333-344.

[2] T. Wakeyama, S. Ehara, Assessment of renewable energy by using GIS- A case study of Unzen city -, Journal of the Japan. Institute of Energy, 88, 2009, pp.58-69.

[3] Grass development team, Welcome to GRASS GIS, 2010, http://grass.itc.it/

[4] Ministry of Land, Infrastructure, Transport and Tourism in Japan (MLIT), Digital national land information, 2010.

[5] New Energy and Industrial Technology Development Organization (NEDO), Local Area Wind Energy Prediction System, NEDO, 2006.

[6] Geological Survey of Japan, AIST, Geothermal Potential Map in Japan, AIST, 2009

[7] New Energy and Industrial Technology Development Organization (NEDO), Biomass GIS Database, NEDO, 2010

[8] H. Kurasaka, Sustinable Zone 2008, Research Center on Public Affairs, 2009 